\title{
Recent advances in the analysis of metal hyperaccumulation and hypertolerance in plants using proteomics
}

\author{
Giovanni DalCorso, Elisa Fasani and Antonella Furini*
}

Department of Biotechnology, University of Verona, Verona, Italy

Edited by:

Mark G. M. Aarts, Wageningen

University, Netherlands

\section{Reviewed by:}

Henk Schat, Vrije Universiteit

Amsterdam, Netherlands

Nathalie Verbruggen, Université

Libre de Bruxelles, Belgium

Sirpa O. Kärenlampi, University of

Eastern Finland, Finland

*Correspondence:

Antonella Furini, Department of Biotechnology, University of Verona, Strada Le Grazie 15, 37134 Verona Italy

e-mail: antonella.furini@univr.it
Hyperaccumulator/hypertolerant plant species have evolved strategies allowing them to grow in metal-contaminated soils, where they accumulate high concentrations of heavy metals in their shoots without signs of toxicity. The mechanisms that allow enhanced metal uptake, root-to-shoot translocation and detoxification in these species are not fully understood. Complementary approaches such as transcriptomic-based DNA microarrays and proteomics have recently been used to gain insight into the molecular pathways evolved by metal hyperaccumulator/hypertolerant species. Proteomics has the advantage of focusing on the translated portion of the genome and it allows to analyze complex networks of proteins. This review discusses the recent analysis of metal hyperaccumulator/hypertolerant plant species using proteomics. Changes in photosynthetic proteins, sulfur, and glutathione metabolism, transport, biotic and xenobiotic defenses as well as the differential regulation of proteins involved in signaling and secondary metabolism are discussed in relation to metal hyperaccumulation. We also consider the potential contribution of several proteins to the hyperaccumulation phenotype.

\section{Keywords: hyperaccumulator/hypertolerance, heavy metals, proteomics, IEF, abiotic stress}

\section{INTRODUCTION}

The ability to hyperaccumulate metals in above-ground tissues without phytotoxic effects has evolved in $\sim 500$ plant species, mainly those in the Brassicaceae family (Krämer, 2010). Most of these species are Ni hyperaccumulators (Baker et al., 2000). At least three processes make a major contribution to the ability to hyperaccumulate/hypertolerate metals: (1) enhanced root uptake and loading into the xylem; (2) superior root-to-shoot translocation; and (3) efficient detoxification via chelation and sequestration, predominantly within leaf cell vacuoles (Clemens et al., 2002). Hyperaccumulators need to regulate their metal homeostasis network precisely. A thorough analysis of the mechanisms involved in metal hyperaccumulation and hypertolerance at the biochemical, genetic and protein levels would provide insight into the corresponding evolutionary and adaptive processes and could be used to develop plants capable of phytoextraction and biofortification. Microarray analysis has been used to compare transcriptional profiles between Arabidopsis thaliana (a non-hyperaccumulator species) and two $\mathrm{Cd} / \mathrm{Zn}$ hyperaccumulator species: Noccaea caerulescens (formerly Thlaspi caerulescens) and Arabidopsis halleri (Becher et al., 2004; Weber et al., 2004; van de Mortel et al., 2006, 2008). These studies indicated that many genes involved in stress responses and metal homeostasis are constitutively expressed at a high level in the hyperaccumulators. The A. halleri transcriptome has also been compared to the non-accumulator species Arabidopsis lyrata ssp. petrea, and to the accumulator and non-accumulator $\mathrm{F}_{3}$ hybrid lines derived by crossing them (Filatov et al., 2006). Similarly, transcription profiles have also been compared between $N$. caerulescens ecotypes with different metal tolerance thresholds and uptake capabilities (Plessl et al., 2010). The ability to tolerate and accumulate metals was found to be associated with the ability to cope with reactive oxygen species (ROS), the expression of metal transporters and the suppression of genes involved in defense and disease resistance. In the abovementioned studies, the modulation of gene expression was considered at the level of transcription/mRNA turnover, which may not directly correlate with the protein level, as has been shown for the putative $\mathrm{Zn}$ and $\mathrm{Mg}$ transporter protein MHX, which is more abundant in A. halleri than in A. thaliana, even though the corresponding transcript levels are not different (Elbaz et al., 2006). Moreover, RNA analyses do not consider the potential impact of protein folding, stability and localization, protein/protein interactions and posttranslational modifications, which are all crucial determinants of protein function. In a proteomic study of the Cd hyperaccumulator Phytolacca americana, for instance, the principal sigma factor of the plastidic RNA polymerase, Sig1, which was enhanced upon $\mathrm{Cd}$ treatment, seems to have undergone some Cd-induced posttranslational modifications (e.g., phosphorylation) that shifted its isoelectric point (Zhao et al., 2011). The proteomic analysis of metal hyperaccumulators is therefore needed to determine the biological functions that arise from changes in gene transcription (Verbruggen et al., 2009). Proteomics not only facilitates the detection of a large number of proteins involved in metal accumulation/detoxification, but also may help to unravel the cross-talk among different pathways. The impact of high metal 


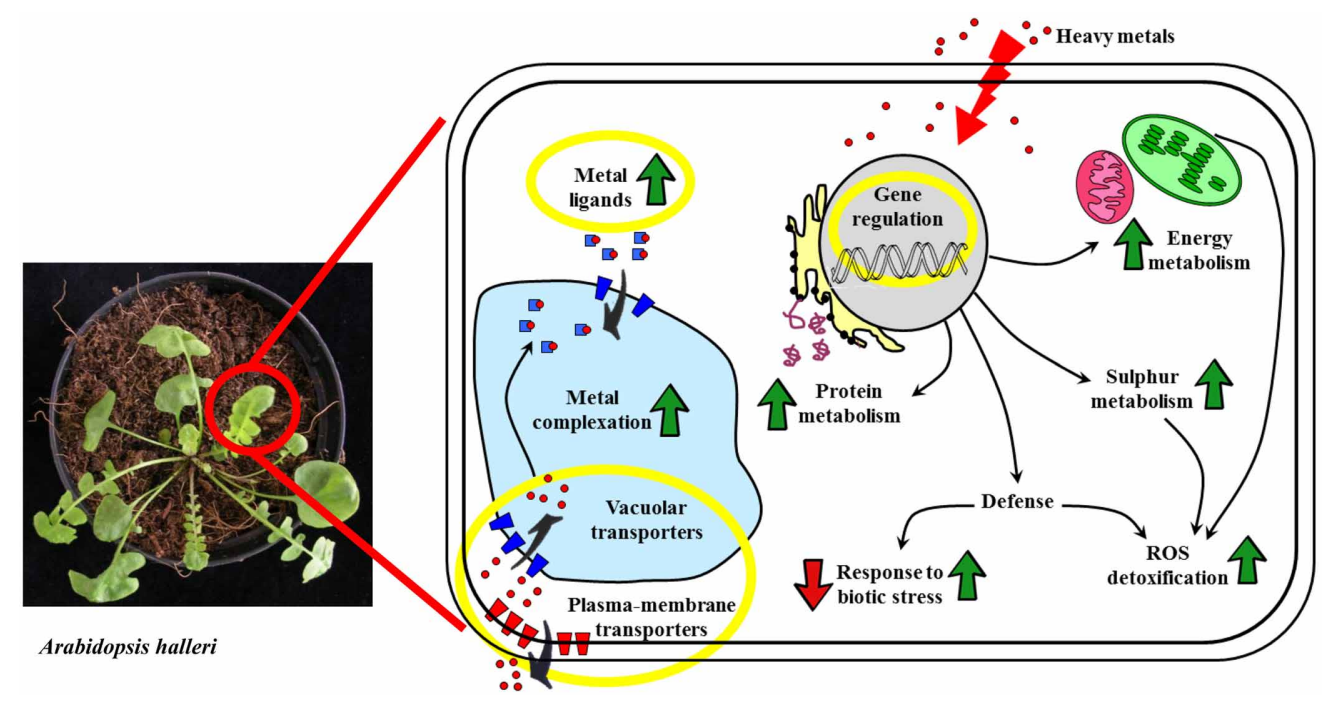

FIGURE 1 | Schematic representation of the cellular mechanisms responsible for the heavy metal accumulation trait that have been identified through differential proteomics approaches. Processes that are involved in metal accumulation but whose actors have not been represented in proteomics results are highlighted by yellow circles. Green arrows mean general up-regulation, red arrows mean down-regulation. Red dots: heavy metal ions. concentrations on the proteome of hyperaccumulator plants has recently been investigated in detail. In this review, we have focused on recent proteomic approaches that highlight the molecular mechanisms and metabolic activities required for hyperaccumulation and detoxification, particularly the analysis of differentially expressed proteins; a schematic representation is reported in Figure 1. We also discuss the limitations of proteomics in the investigation of hyperaccumulator plants.

\section{PHOTOSYNTHESIS AND ENERGY METABOLISM}

The most recent proteomic experiments show that many of the proteins modulated in hyperaccumulator plants represent the photosynthetic machinery, reflecting the abundance of photosynthetic proteins in green tissues. Interestingly, even though the efficiency of photosynthesis (measured as the photosynthetic quantum yield) is not affected by heavy metals, these proteins tend to be induced by heavy metal treatment (Farinati et al., 2009). In A. halleri, $\mathrm{Cd}$ and $\mathrm{Zn}$ treatment induced the over-accumulation of subunits of antenna systems and photosystems, the cytochrome $\mathrm{b}_{6} / \mathrm{f}$ complex and the ATPase complex (Farinati et al., 2009). Similarly, polypeptide spots corresponding to ribulose bisphosphate carboxylase/oxygenase (RuBisCO), ATPase subunits and oxygen evolving complex (OEC) proteins 1 and 2 accumulated when As was applied to the pseudometallophytes Agrostis tenuis (Duquesnoy et al., 2009) and Pteris vittata (Bona et al., 2010). In the $\mathrm{Zn}$ and Cd hyperaccumulator Arabis paniculata, moderate exposure to $\mathrm{Zn}$ enhanced the expression of OEC components, whereas excess $\mathrm{Zn}$ induced the downregulation of RuBisCO activase thus lowering the efficiency of $\mathrm{CO}_{2}$ assimilation (Zeng et al., 2011). The upregulation of photosynthetic proteins under metal exposure might be explained by an increased cellular energy demand, imposed by the hyperaccumulation process. Accordingly, the upregulation of Calvin-Benson cycle enzymes (e.g., RuBisCO, RuBisCO activase, phosphoribulokinase (PRK), and fructose-bisphosphate aldolase) may be necessary to avoid the inhibition of the electron flow through the photosystems (Farinati et al., 2011; Visioli and Marmiroli, 2013). Alternatively, hyperaccumulators usually exhibit strongly enhanced requirements for $\mathrm{Zn}$, even to such an extent that they may suffer from $\mathrm{Zn}$ deficiency when growing at $\mathrm{Zn}$ supply rates that are considered to be luxurious for nonaccumulator plants (van de Mortel et al., 2006). Therefore, the enhanced abundance of photosynthetic proteins, imposed by $\mathrm{Zn}$ exposure, may also be taken to reflect an enhanced scope for growth due to improved $\mathrm{Zn}$ nutrition. It is notable that different heavy metals induce different responses. Indeed, although feeble Cd treatments seem to enhance chlorophyll and carotenoid content in the Cd hyperaccumulator Lonicera japonica (Jia et al., 2013), in other species, such as the Cd hyperaccumulators $P$. americana and $N$. caerulescens, $\mathrm{Cd}$ suppresses photosynthetic proteins and some enzymes of the Calvin-Benson cycle, e.g., RuBisCO and PRK (Hossain and Komatsu, 2012). This has been interpreted as a symptom of $\mathrm{Cd}$ toxicity because $\mathrm{Zn}$ treatment promotes the activity of RuBisCO and OEC proteins in the same species (Tuomainen et al., 2006; Zhao et al., 2011).

\section{SULFUR METABOLISM}

Heavy metals have a strong impact on sulfur metabolism because it plays an essential role in metal detoxification, and the modulation of proteins involved in sulfur metabolism has been observed using proteomic approaches in several different hyperaccumulators (Ingle et al., 2005b; Alvarez et al., 2009; Farinati et al., 2009; Bona et al., 2010; Tuomainen et al., 2010; Zeng et al., 2011; Zhao et al., 2011; Schneider et al., 2013). Cysteine biosynthesis is generally induced by heavy metals, e.g., the enzymes serine hydroxymethyltransferase (SHMT, Ingle et al., 2005b), serine acetyltransferase (SAT, Bona et al., 2010) and Oacetylserine(thiol)lyase (OASTL, Ingle et al., 2005b; Bona et al., 
2010; Schneider et al., 2013). Interestingly, methionine biosynthesis is suppressed in Alyssum lesbiacum, indicating that thiol groups are diverted toward cysteine and glutathione (GSH) biosynthesis (Ingle et al., 2005b). In contrast, methionine synthase was induced after metal treatment in P. americana (Zhao et al., 2011), suggesting there are diverse strategies for metal detoxification in hyperaccumulator species. Indeed, methionine is converted into S-adenosylmethionine, which is a precursor in many biosynthetic pathways including nicotianamine (NA) (Higuchi et al., 1999). The cysteine produced in hyperaccumulators enters the GSH biosynthetic pathway, although proteomic analysis has not identified an upregulated enzyme responsible for GSH biosynthesis. However, glutathione-S-transferase (GST) proteins, mainly members of the phi class of GST, i.e., GSTFs, were shown to be upregulated upon metal treatment in N. caerulescens (Tuomainen et al., 2010; Schneider et al., 2013), A. lesbiacum (Ingle et al., 2005b), A. paniculata (Zeng et al., 2011), Brassica juncea (Alvarez et al., 2009) and P. americana (Zhao et al., 2011). GSTFs are involved in the detoxification of xenobiotics by conjugation to GSH (Frova, 2003) and this confirms the role of GSH in metal detoxification not only in the context of ROS scavenging, but also metal ion binding and transport. Furthermore, GSH is the substrate for phytochelatin (PC) biosynthesis, which promotes metal detoxification by chelation. However, PCs are found mainly in non-accumulator species such as A. thaliana (Sarry et al., 2006) and Brassica napus (Mendoza-Cózatl et al., 2008). Conversely, hyperaccumulator species $A$. halleri and $N$. caerulescens produce very low levels of PCs, although they constitutively express functional phytochelatin synthetase (PCS) genes (Meyer et al., 2011) suggesting they have PC-independent mechanisms for metal sequestration.

\section{NITROGEN AND PROTEIN METABOLISM}

The impact of heavy metals on plant metabolism means that metal hypertolerant/hyperaccumulator species must possess mechanisms for more efficient protein turnover. Proteomic analysis has revealed the modulation or specific induction of several proteins involved in protein metabolism in $N$. caerulescens (Tuomainen et al., 2006), A. lesbiacum (Ingle et al., 2005b), A. paniculata (Zeng et al., 2011), B. juncea (Alvarez et al., 2009), P. americana (Zhao et al., 2011) and P. vittata (Bona et al., 2010). Heavy metals have been shown to affect transcription and translation (Alvarez et al., 2009; Bona et al., 2010; Zeng et al., 2011; Zhao et al., 2011; Visioli et al., 2012), protein folding (Ingle et al., 2005b; Tuomainen et al., 2006; Alvarez et al., 2009; Zeng et al., 2011; Zhao et al., 2011), and protein degradation (Alvarez et al., 2009; Zeng et al., 2011; Visioli et al., 2012). These processes are also induced by metal treatment in non-accumulator species such as A. thaliana (Sarry et al., 2006), suggesting a common role in the response to heavy metal stress (Ingle et al., 2005b). However, an essential role in metal accumulation and tolerance is indicated by the differential regulation of proteins involved in protein folding among $N$. caerulescens accessions showing different levels of metal tolerance (Tuomainen et al., 2006) and in Cd-accumulating soybean cultivars (Ahsan et al., 2012). As an alternative explanation, high metal levels may induce increased growth in hyperaccumulator plants characterized by high metal requirement, such as
N. caerulescens (Shen et al., 1997), leading to enhanced protein metabolism. Higher rates of protein turnover require higher rates of $\mathrm{N}$ assimilation, thus explaining the induction of glutamine synthetase in hyperaccumulator species such as $N$. caerulescens (Tuomainen et al., 2006), A. paniculata (Zeng et al., 2011) and $P$. vittata (Bona et al., 2011) following exposure to heavy metals to meet the increased demand for nitrogenous compounds.

\section{DEFENSE-RELATED PROTEINS}

Any disruption of the cellular redox status can produce ROS, and plants have evolved a range of mechanisms to detoxify these molecules thus reducing the impact of metal stress. Although hyperaccumulators possess efficient metal chelation systems (Hall, 2002), some also induce the expression of proteins implicated in oxidative defense, e.g., LADH (a putative NADPdependent oxidoreductase), GST and a mannose-6-phosphate reductase were induced in A. lesbiacum after short-term exposure to $0.3 \mathrm{mM} \mathrm{NiSO}_{4}$, whereas longer exposure to $0.03 \mathrm{mM} \mathrm{NiSO}_{4}$ (sufficient to produce Ni hyperaccumulation in the shoot) did not induce these proteins (Ingle et al., 2005b). Similarly, antioxidant defense proteins such as 2-Cys-peroxiredoxin (2CysPrx) were induced in Cd-treated P. americana seedlings. The mature protein 2CysPrx is targeted to the chloroplasts, where it potentially plays a role in the detoxification of $\mathrm{H}_{2} \mathrm{O}_{2}$ (Zhao et al., 2011). Similarly, glutathione peroxidase (GPX), catalase and heat-shock-proteins (HSP) were induced in the fronds of $P$. vittata plants (Bona et al., 2010), whereas iron-superoxide dismutase (Fe-SOD) and glyoxalase I (GLXI) were induced and GSTF2 was down-regulated in A. halleri plants treated with Zn and Cd (Farinati et al., 2009). The induction of GST is usually associated with metal stress (Roth et al., 2006), so the suppression of GSTF2 in A. halleri suggested that in this hyperaccumulator species symptoms associated with the metal-induced oxidative stress might be alleviated. The inoculation of metal-treated $P$. vittata plants with mycorrhizal fungi and $A$. halleri plants with rhizobacteria suppresses these proteins, suggesting a general improvement of plant fitness due to their interaction with microorganisms (Farinati et al., 2009; Bona et al., 2010). Further analysis showed that ROS scavenging enzymes in $P$. vittata were not detected in the root proteome except for the upregulation of aldehyde dehydrogenase (Bona et al., 2010), a general detoxifying enzyme correlated with stress tolerance (Sunkar et al., 2003). The measurement of protein levels in the leaf epidermal and mesophyll tissues of $\mathrm{Zn}$-hyperaccumulating accessions of $N$. caerulescens revealed that the epidermis adapts to extreme Zn concentrations by accumulating more GST and GSH, ensuring protection against oxidative stress (Schneider et al., 2013). Proteomic analysis revealed that A. paniculata expressed different proteins upon $\mathrm{Zn}$ or $\mathrm{Cd}$ treatment. For instance, $\mathrm{Zn}$ treatment induced both energy metabolism and proteins related to stress-scavenging strategies (e.g., ATB2), in the shoot, while xenobiotic/antioxidant strategies were enhanced in Cd-treated plants (Zeng et al., 2011). Interestingly, non-toxic level of heavy metals (beneficial or toxic) can stimulate the growth of several hyperaccumulators and this could be due to both a beneficial effect of improved metal nutrition and/or the activation of mechanisms that are usually deputed to the stress-scavenge. Proteins involved in the jasmonic acid (JA) and salicylic acid (SA) signaling 
pathways are also modulated in metal hyperaccumulators, e.g., allene oxide cyclase, an essential enzyme in the JA biosynthesis pathway, is downregulated in the shoots of $A$. halleri plants treated with Cd and Zn (Farinati et al., 2009). Under the same conditions, vegetative storage proteins are also strongly suppressed. These proteins function as temporary amino acid stores during plant development, although they also respond to JA (Matthes et al., 2008) and possess acid phosphatase activity that deters insect pests (Liu et al., 2005). High concentrations of metals in Alyssum bertolonii (Ernst, 1990) and N. caerulescens (Tolrà et al., 2001) are known to reduce the levels of glucosinolates in shoots. Similarly, when A. halleri is treated with $\mathrm{Cd}$ and $\mathrm{Zn}$, there is a greater than tenfold inhibition in the activity of the $\beta$ thioglucoside glucohydrolase, a myrosinase enzyme that breaks down glucosinolates into metabolites that are toxic toward herbivores (Farinati et al., 2009). Furthermore, a $\beta$-glucanase with anti-fungal activity was inhibited in $P$. vittata following exposure to As (Bona et al., 2011). Taken together, these results suggest that heavy metal hyperaccumulation downregulates the complex signaling networks that mediate plant defenses against herbivores, insects and pathogens. This supports the controversial hypothesis that metal accumulation in plants provides elemental defense against biotic stress (Boyd et al., 2002; Pollard et al., 2002) which involves cross-talk between heavy metal and defense signaling. On the other hand, proteomic analysis has shown that metals can also induce proteins implicated in biotic stress responses. In A. thaliana, several proteomic studies have shown that defense mechanisms activated by pathogens also protect against Cd toxicity (Sels et al., 2008). N. caerulescens accessions growing in metalliferous soil express higher levels of $\beta$-1,3-glucanase than accessions growing in normal soil (Tuomainen et al., 2010). This pathogenesis-related enzyme is part of the cellulose biosynthesis pathway and may facilitate cell wall restructuring to protect plants from both pathogens and excess metal (van de Mortel et al., 2008). The proteomic analysis of N. caerulescens accessions growing in Ni-contaminated soil revealed the induction of an antifungal protein and several defensin-like proteins (Visioli et al., 2012), that are normally induced by pathogens (Carvalho and Gomes, 2009). Defensins are also induced by drought, salinity, cold and signaling through the JA, SA and ethylene pathways (Hanks et al., 2005). The modulation of proteins related to biotic and abiotic stress in hyperaccumulator species and accessions supports their evolutionary plasticity as a result of selection in different environments and genotypic control of the resulting phenotypes.

\section{METAL LIGANDS}

A key metal hyperaccumulation strategy is the ability to chelate metals for detoxification and transport. As discussed above, thiol compounds such as GSH and PCs can bind metals, but only GSH seems to play this role in hyperaccumulator species (Ingle et al., 2005b; Alvarez et al., 2009; Farinati et al., 2009; Tuomainen et al., 2010; Zeng et al., 2011; Zhao et al., 2011; Schneider et al., 2013). $\mathrm{NA}$ is the principal ligand for $\mathrm{Zn}$ in A. halleri (Deinlein et al., 2012) and N. caerulescens (Schneider et al., 2013), and transcriptomic studies have confirmed that the nicotianamine synthase (NAS) gene is highly expressed in hyperaccumulators compared to non-accumulators (Becher et al., 2004; Weber et al., 2004; van de Mortel et al., 2006, 2008). Although no modulation of proteins involved in NA biosynthesis was observed in proteomic analysis, methionine biosynthesis is upregulated in P. americana following metal treatment (Zhao et al., 2011) and this may be required to increase the NA pool in the presence of heavy metals. The amino acid histidine is the major Ni ligand in A. lesbiacum and $N$. caerulescens, and it plays an important role in Ni tolerance and accumulation (Ingle et al., 2005a; Richau et al., 2009). Even so, proteomic analysis has shown that the key enzyme in the histidine biosynthesis pathway (ATP-PRT) is not modulated by metal treatment (Ingle et al., 2005b). Finally, several metallothioneins (MTs), small cysteine-rich metal-binding proteins, are highly expressed in particular ecotypes of $N$. caerulescens. However, high MT expression levels did neither co-segregate with $\mathrm{Zn}$ or $\mathrm{Cd}$ hyperaccumulation capacity, nor with $\mathrm{Zn}$ or $\mathrm{Cd}$ tolerance capacity, analyzed in segregating inter-ecotypic crosses, suggesting that these peptides might be primarily involved in $\mathrm{Cu}$ homeostasis, rather than $\mathrm{Zn}$ or $\mathrm{Cd}$ hyperaccumulation/hypertolerance traits as such (Roosens et al., 2004; Hassinen et al., 2009). Proteomic analysis in the same species showed that MT-4C was more abundant in populations characterized by more efficient metal translocation in the shoot (Visioli et al., 2012). It is interesting to note that few proteins responsible for metal ligand biosynthesis have been identified by proteomic analysis, but this does not indicate a lack of involvement in metal tolerance. Indeed, transcriptomic analysis indicates that the corresponding genes may be constitutively expressed at a high level in hyperaccumulators, providing longterm protection against heavy metal stress (Becher et al., 2004; Weber et al., 2004; van de Mortel et al., 2006, 2008).

\section{MEMBRANE TRANSPORTERS}

Membrane proteins are usually classified as integral membrane proteins, characterized by multiple transmembrane regions that anchor the protein into the phospholipid bilayer, or membraneassociated proteins, which are loosely bound to other protein complexes and easily washed away during sample preparation. The standard two-dimensional gel-based 2D proteomic approach for the analysis of complex protein samples involves isoelectric focusing (IEF) followed by sodium dodecylsulfate polyacrylamide gel electrophoresis (SDS-PAGE). Unfortunately, even if characterized by a very high resolution, possibly combinable with quantitative approaches (Rose et al., 2004), IEF is rather poorly compatible with proteomics of integral membrane proteins. In fact, the solubility of membrane proteins is at a minimum when they are at their isoelectric point, resulting in protein precipitation that precludes the following transfer onto the second dimension (Garbis et al., 2005; Speers and Wu, 2007). Strong detergents such as SDS that could solubilize integral membrane proteins are also incompatible with IEF (Speers and Wu, 2007). Because of these inherent difficulties, the importance of membrane-localized metal transporters for metal detoxification and hyperaccumulation was initially determined by transcriptomic analysis followed by protein characterization (Assunção et al., 2001; Becher et al., 2004; Papoyan and Kochian, 2004; Weber et al., 2004). However, gel-based proteomics can be replaced with two-dimensional liquid chromatography/mass spectrometry, which provides a versatile environment suitable for the quantitative analysis of membrane proteins. This approach has identified a P-type ATPase 
and a ZRT/IRT-like protein (ZIP) transporter in $N$. caerulescens homologous to the A. thaliana proteins AtHMA4 and AtZIP4, respectively. In $N$. caerulescens, these were found to be more abundant in the epidermis than in the mesophyll, whereas HMA4 was shown to be confined to the plasma membrane of xylem parenchymatic cells of A. halleri (Schneider et al., 2013). This approach also identified NcMTP1 (the N. caerulescens homolog of AtZAT/MTP1) which was found to be more abundant, but not enriched, in the epidermis, and NcHMA3, a P-type ATPase that was shown to be significantly enriched in the mesophyll tissue (Schneider et al., 2013). A similar procedure was applied to diverse $N$. caerulescens populations growing in ophiolitic soils, resulting in the identification of ABC27, an ATP binding cassette transporter that was more abundant in the presence of heavy metals and may be involved in the sequestration of metal ions into vacuoles and other subcellular compartments, and in their export across the cell wall (Visioli et al., 2012).

\section{CONCLUDING REMARKS: PROTEOMICS LIMITATIONS AND CHALLENGES}

One of the first challenges encountered by plant scientists using proteomics is sample preparation. Reproducibly is essential to ensure that the full complement of proteins in a given sample is captured and separated, and also that operator artifacts and non-proteinaceous contaminants are minimized. Factors such as recalcitrant components (e.g., cellulose and lignin of the cell wall) and plant metabolites (e.g., phenolic compounds, starch and other carbohydrates) often compromise the extraction process, reducing the protein yield and interfering with fractionation and protein separation (Visioli and Marmiroli, 2013). Moreover, the low abundance of key proteins such as membrane transporters and transcription factors, does prevent their detection after sample preparation and protein separation (Garbis et al., 2005). The diverse characteristics of proteins, including size, mass, charge, hydrophobicity, conformational states, post-translational modifications and the formation of complexes, mean that no protocol can accurately recover the entire proteome for a given sample. Such limitations are particularly evident in the case of membrane proteins, as discussed above, excluding the most relevant proteins (trans-membrane transporters) from being represented. To address these challenges, alternative gel-based approaches have been developed in an attempt to maintain the native protein

\section{REFERENCES}

Ahsan, N., Nakamura, T., and Komatsu, S. (2012). Differential responses of microsomal proteins and metabolites in two contrasting cadmium (Cd)-accumulating soybean cultivars under Cd stress. Amino Acids 42, 317-327. doi: 10.1007/s00726010-0809-7

Alvarez, S., Berla, B. M., Sheffield, J., Cahoon, R. E., Jez, J. M., and Hicks, L. M. (2009). Comprehensive analysis of the Brassica juncea root proteome in response to cadmium exposure by complementary proteomic approaches.
Proteomics 9, 2419-2431. doi: 10.1002/pmic. 200800478

Assunção, A. G. L., Martins, P. D. A. C., Folter, S. D. E., Vooijs, R., Schat, H., and Aarts, M. G. M. (2001). Elevated expression of metal transporter genes in three accessions of the metal hyperaccumulator Thlaspi caerulescens. Plant Cell Environ. 3, 217-226. doi: 10.1111/j.13653040.2001.00666.x

Baker, A. J. M., McGrath, S. P., Reeves, R. D., and Smith, J. A. C. (2000). "Chapter 5. Metal hyperaccumulator plants: a review of the ecology and physiology of

conformation, e.g., Blue Native PAGE uses the dye Coomassie Brilliant Blue G-250 to bind exposed hydrophobic domains thus conferring a net negative charge that enhances electrophoretic mobility and solubilization and thus allows membrane proteins to be separated avoiding precipitation as in IEF (Wittig and Schägger, 2009). Various gel-free approaches have been also developed (Speers and Wu, 2007). Another limitation of differential proteomics is the inability to identify relevant proteins that are constitutively expressed. Even if the abundance of a given protein does not change before and after metal treatment, this does not necessarily indicate that it has no role in metal hyperaccumulation. On the contrary, transcriptomic analysis often shows that genes responsible for hyperaccumulation are strongly and constitutively expressed, suggesting that the hyperaccumulation trait is constitutive and the corresponding proteins are not induced in response to metals but are available all the time (Becher et al., 2004; Weber et al., 2004; van de Mortel et al., 2006, 2008). Therefore, the most informative comparisons are not of hyperaccumulator proteomes before and after exposure to heavy metals, but of proteomes from hyperaccumulator and non-accumulator species/accessions. This strategy has already been tested using the hyperaccumulator A. lesbiacum and its non-accumulating close relative $A$. montanum, but the proteomes were too different for meaningful comparison (Ingle et al., 2005b). Comparisons between hyperaccumulator and non-accumulator accessions of the same species may therefore be the most productive way forward to gain insight into the mechanisms of metal hypertolerance and hyperaccumulation. However, even intra-specific comparisons between accessions with contrasting accumulation or tolerance capacities are likely to be confounded by divergent selection under the pressure of factors other than metals themselves. For example, the great majority of proteins that appeared to be differentially expressed among $N$. caerulescens accessions with contrasting accumulation and tolerance capacities, were not differentially expressed among sets of recombinant lines selected for contrasting accumulation and tolerance from inter-accession crosses. Moreover, none of the identified proteins of which the expression level did co-segregate with tolerance or accumulation capacity seemed to have any conceivable role in metal homeostasis (Tuomainen et al., 2010). Therefore, proteomics-based hypotheses concerning the molecular and biochemical mechanisms of hyperaccumulation always need a rigid genetic confirmation.

a biological resource for phytoremediation of metal-polluted soils," in Phytoremediation of Contamined Soil and Water, eds N. Terry and G. Bañuelos (Boca Raton, FL: CRC Press), 85-107.

Becher, M., Talke, I. N., Krall, L., and Krämer, U. (2004). Crossspecies microarray transcript profiling reveals high constitutive expression of metal homeostasis genes in shoots of the zinc hyperaccumulator Arabidopsis halleri. Plant J. 37, 251-268. doi: 10.1046/j.1365313X.2003.01959.X
Bona, E., Cattaneo, C., Cesaro, P. Marsano, F., Lingua, G., Cavaletto, M., et al. (2010). Proteomic analysis of Pteris vittata fronds: two arbuscular mycorrhizal fungi differentially modulate protein expression under arsenic contamination. Proteomics 10, 3811-3834. doi: 10.1002/pmic.200900436

Bona, E., Marsano, F., Massa, N., Cattaneo, C., Cesaro, P., Argese, E., et al. (2011). Proteomic analysis as a tool for investigating arsenic stress in Pteris vittata roots colonized or not by arbuscular mycorrhizal symbiosis. J. Proteomics 74, 
1338-1350. doi: 10.1016/j.jprot. 2011.03.027

Boyd, R. S., Davis, M. A., Wall, M. A., and Balkwill, K. (2002). Nickel defends the South African hyperaccumulator Senecio coronatus (Asteraceae) against Helix aspersa (Mullusca: Pulmonidae). Chemoecology 12, 91-97. doi: 10.1007/s00049-002-8331-3

Carvalho, A. O., and Gomes, V. M. (2009). Plant defensins - prospects for the biological functions and biotechnological properties. Peptides 30, 1007-1020. doi: 10.1016/j.peptides.2009.01.018

Clemens, S., Palmgren, M. G., and Krämer, U. (2002). A long way ahead: understanding and engineering plant metal accumulation. Trends Plant Sci. 7, 309-315. doi: 10.1016/S1360-138502295-1

Deinlein, U., Weber, M., Schmidt, H., Rensch, S., Trampczynska, A., Hansen, T. H., et al. (2012). Elevated nicotianamine levels in Arabidopsis halleri roots play a key role in zinc hyperaccumulation. Plant Cell 24, 708-723. doi: 10.1105/tpc.111.095000

Duquesnoy, I., Goupil, P., Nadaud, I., Branlard, G., Piquet-Pissaloux, A., and Ledoigt, G. (2009). Identification of Agrostis tenuis leaf proteins in response to $\mathrm{As}(\mathrm{V})$ and $\mathrm{As}(\mathrm{III})$ induced stress using a proteomics approach. Plant Sci. 176, 206-213. doi: 10.1016/j.plantsci.2008.10.008

Elbaz, B., Shoshani-Knaani, N., DavidAssael, O., Mizrachy-Dagri, T., Mizrahi, K., Saul, H., et al. (2006). High expression in leaves of the zinc hyperaccumulator Arabidopsis halleri of AhMHX, a homolog of an Arabidopsis thaliana vacuolar metal/proton exchanger. Plant Cell Environ. 29, 1179-1190. doi: 10.1111/j.1365-3040.2006.01500.x

Ernst, W. H. O. (1990). "Mine vegetation in Europe," in Heavy Metal Tolerance in Plants: Evolutionary Aspects, ed A. J. Shaw (Boca Raton, FL: CRC Press), 21-37.

Farinati, S., DalCorso, G., Bona, E., Corbella, M., Lampis, S., Cecconi, D., et al. (2009). Proteomic analysis of Arabidopsis halleri shoots in response to the heavy metals cadmium and zinc and rhizosphere microorganisms. Proteomics 9, 4837-4850. doi: 10.1002/pmic. 200900036

Farinati, S., DalCorso, G., Panigati, M., and Furini, A. (2011). Interaction between selected bacterial strains and Arabidopsis halleri modulates shoot proteome and cadmium and zinc accumulation. J. Exp.
Bot. 62, 3433-3447. doi: 10.1093/ jxb/err015

Filatov, V., Dowdle, J., Smirnoff, N., Ford-Lloyd, B., Newbury, H. J., and MacNair, M. R. (2006). Comparison of gene expression in segregating families identifies genes and genomic regions involved in a novel adaptation, zinc hyperaccumulation. Mol. Ecol. 15, 3045-3059. doi: 10.1111/j.1365-294X.2006.02981.x

Frova, C. (2003). The plant glutathione transferase gene family: genomic structure, functions, expression and evolution. Physiol. Plantarum 119, 469-479. doi: 10.1046/j.1399-3054.2003.00183.x

Garbis, S., Lubec, G., and Fountoulakis, M. (2005). Limitations of current proteomics technologies. J. Chromatogr. 1077, 1-18. doi: 10.1016/j.chroma.2005.04.059

Hall, J. L. (2002). Cellular mechanisms for heavy metal detoxification and tolerance. J. Exp. Bot. 53, 1-11. doi: 10.1093/jexbot/53.366.1

Hanks, J. N., Snyder, A. K., Graham, M. A., Shah, R. K., Blaylock, L. A., Harrison, M. J., et al. (2005). Defensin gene family in Medicago truncatula: structure, expression and induction by signal molecules. Plant Mol. Biol. 58, 385-399. doi: 10.1007/s11103-005-5567-7

Hassinen, V. H., Tuomainen, M., Peräniemi, S., Schat, H., Kärenlampi, S. O., and Tervahauta, A I. (2009). Metallothioneins 2 and 3 contribute to the metaladapted phenotype but are not directly linked to $\mathrm{Zn}$ accumulation in the metal hyperaccumulator, Thlaspi caerulescens. J. Exp. Bot. 60, 187-196. doi: 10.1093/jxb/ern287

Higuchi, K., Suzuki, K., Nakanishi, H., Yamaguchi, H., Nishizawa, N. K., and Mori, S. (1999). Cloning of nicotianamine synthase genes, novel genes involved in the biosynthesis of phytosiderophores. Plant Physiol. 119, 471-480. doi: 10.1104/pp.119.2.471

Hossain, Z., and Komatsu, S. (2012). Contribution of proteomic studies towards understanding plant heavy metal stress response. Front. Plant Sci. 3:310. doi: 10.3389/fpls.2012.00310

Ingle, R. A., Mugford, S. T., Rees, J. D., Campbell, M. M., and Smith, J. A. C. (2005a). Constitutively high expression of the histidine biosynthetic pathway contributes to nickel tolerance in hyperaccumulator plants. Plant Cell 17, 2089-2106. doi: 10.1105/tpc.104.030577

Ingle, R. A., Smith, J. A. C., and Sweetlove, L. J. (2005b). Responses to nickel in the proteome of the hyperaccumulator plant Alyssum lesbiacum. Biometals 18, 627-641. doi: 10.1007/s10534-005-2999-0

Jia, L., He, X., Chen, W., Liu, Z., Huang, Y., and Yu, S. (2013) Hormesis phenomena under Cd stress in a hyperaccumulatorLonicera japonica Thunb. Ecotoxicology 22, 476-485. doi: 10.1007/s10646-013-1041-5

Krämer, U. (2010). Metal hyperaccumulation in plants. Annu. Rev. Plant Biol. 61, 517-534. doi: $\quad 10.1146 /$ annurev-arplant042809-112156

Liu, Y., Ahn, J.-E., Datta, S., Salzman, R. A., Moon, J., Huyghues-Despointes, B., et al. (2005). Arabidopsis vegetative storage protein is an anti-insect acid phosphatase. Plant Physiol. 139, 1545-1556. doi: 10.1104/pp. 105.066837

Matthes, M. C., Pickett, J. A., and Napier, J. A. (2008). Natural variation in responsiveness of Arabidopsis thaliana to methyl jasmonate is developmentally regulated. Planta 228, 1021-1028. doi 10.1007/s00425-008-0804-3

Mendoza-Cózatl, D. G., Butko, E., Springer, F., Torpey, J. W., Komives, E. A., Kehr, J., et al. (2008). Identification of high levels of phytochelatins, glutathione and cadmium in the phloem sap of Brassica napus. A role for thiolpeptides in the long-distance transport of cadmium and the effect of cadmium on iron translocation. Plant J. 54, 249-259. doi: 10.1111/j.1365-313X.2008.03410.x

Meyer, C.-L., Peisker, D., Courbot, M., Craciun, A. R., Cazalé, A.C., Desgain, D., et al. (2011). Isolation and characterization of Arabidopsis halleri and Thlaspi caerulescens phytochelatin synthases. Planta 234, 83-95. doi: 10.1007/s00425-011-1378-z

Papoyan, A., and Kochian, L. V. (2004). Identifcation of Thlaspi caerulescens genes that may be involved in heavy metal hyperaccumulation and tolerance. Characterization of a novel heavy metal transporting ATPase. Plant Physiol. 136, 3814-3823. doi: 10.1104/pp.104.044503

Plessl, M., Rigola, D., Hassinen, V. H., Tervahauta, A., Kärenlampi, S., Schat, H., et al. (2010). Comparison of two ecotypes of the metal hyperaccumulator Thlaspi caerulescens (J. and C. PRESL) at the transcriptional level. Protoplasma 239, 81-93. doi: 10.1007/s00709-0090085-0

Pollard, A. J., Dandridge Powell, K., Harper, F. A., and Smith, J. A. C. (2002). The genetic basis of metal hyperaccumulation in plants. Crit. Rev. Plant Sci. 21, 539-566. doi: 10.1080/0735-260291044359

Richau, K. H., Kozhevnikova, A. D. Seregin, I. V., Vooijs, R., Koevoets, P. L. M., Smith, J. A. C., et al. (2009). Chelation by histidine inhibits the vacuolar sequestration of nickel in roots of the hyperaccumulator Thlaspi caerulescens. New Phytol. 183, 106-116. doi: 10.1111/j.14698137.2009.02826.x

Rose, J. K. C., Bashir, S., Giovannoni, J. J., Jahn, M. M., and Saravanan, R. S. (2004). Tackling the plant proteome: practical approaches, hurdles and experimental tools. Plant J. 39, 715-733. doi: 10.1111/j.1365313X.2004.02182.x

Roosens, N. H., Bernard, C., Leplae, R., and Verbruggen, N. (2004). Evidence for copper homeostasis function of metallothionein (MT3) in the hyperaccumulator Thlaspi caerulescens. FEBS Lett. 577, 9-16. doi: 10.1016/j.febslet.2004.08.084

Roth, U., Von Roepenack-Lahaye, E., and Clemens, S. (2006). Proteome changes in Arabidopsis thaliana roots upon exposure to $\mathrm{Cd}^{2+}$. J. Exp. Bot. 57, 4003-4013. doi: 10.1093/jxb/erl170

Sarry, J.-E., Kuhn, L., Ducruix, C., Lafaye, A., Junot, C., Hugouvieux, V., et al. (2006). The early responses of Arabidopsis thaliana cells to cadmium exposure explored by protein and metabolite profiling analyses. Proteomics 6, 2180-2198. doi: 10.1002/pmic.200 500543

Schneider, T., Persson, D. P., Husted, S., Schellenberg, M., Gehrig, P., Lee, Y., et al. (2013). A proteomics approach to investigate the process of $\mathrm{Zn}$ hyperaccumulation in Noccaea caerulescens (J and C. Presl) F.K. Meyer. Plant J. 73, 131-142. doi: $10.1111 /$ tpj. 12022

Sels, J., Mathys, J., De Coninck, B. M., Cammue, B. P., and De Bolle, M. F. C. (2008). Plant pathogenesis-related (PR) proteins: a focus on PR peptides. Plant Physiol. Biochem. 46, 941-950. doi: 10.1016/j.plaphy.2008.06.011

Shen, Z. G., Zhao, F. J., and McGrath, S. (1997). Uptake and transport of zinc in the hyperaccumulator Thiaspi caerulescens and the non-hyperaccumulator Thiaspi ochroleucum. Plant Cell Environ. 20, 898-906. doi: 10.1046/j.13653040.1997.d01-134.x

Speers, A. E., and Wu, C. C. (2007). Proteomics of integral membrane proteins-theory and application. Chem. Rev. 107, 3687-3714. doi: $10.1021 / \mathrm{cr} 068286 \mathrm{z}$ 
Sunkar, R., Bartels, D., and Kirch, H. H. (2003). Overexpression of a stressinducible aldehyde dehydrogenase gene from Arabidopsis thaliana in transgenic plants improves stress tolerance. Plant J. 35, 452-464. doi: 10.1046/j.1365-313X. 2003.01819.x

Tolrà, R. P., Poschenrieder, C., Alonso, R., Barceló, D., and Barceló, J. (2001). Influence of zinc hyperaccumulation on glucosinolates in Thlaspi caerulescens. New Phytol. 151, 621-626. doi: 10.1046/j.0028646x.2001.00221.x

Tuomainen, M., Tervahauta, A., Hassinen, V., Schat, H., Koistinen, K. M., Lehesranta, S., et al. (2010). Proteomics of Thlaspi caerulescens accessions and an inter-accession cross segregating for zinc accumulation. J. Exp. Bot. 61, 1075-1087. doi: 10.1093/jxb/erp372

Tuomainen, M. H., Nunan, N., Lehesranta, S. J., Tervahauta, A. I., Hassinen, V. H., Schat, H., et al. (2006). Multivariate analysis of protein profiles of metal hyperaccumulator Thlaspi caerulescens accessions. Proteomics 6, 3696-3706. doi: 10.1002/pmic.200501357

van de Mortel, J. E., Almar Villanueva, L., Schat, H., Kwekkeboom, J., Coughlan, S., Moerland, P. D., et al. (2006). Large expression differences in genes for iron and zinc homeostasis, stress response, and lignin biosynthesis distinguish roots of Arabidopsis thaliana and the related metal hyperaccumulator Thlaspi caerulescens. Plant Physiol. 142, 1127-1147. doi: 10.1104/pp.106.082073

van de Mortel, J. E., Schat, H., Moerland, P. D., Ver Loren van Themaat, E., van der Ent, S., Blankestijn, H., et al. (2008). Expression differences for genes involved in lignin, glutathione and sulphate metabolism in response to cadmium in Arabidopsis thaliana and the related $\mathrm{Zn} / \mathrm{Cd}$-hyperaccumulator Thlaspi caerulescens. Plant Cell Environ. 31, 301-324. doi: 10.1111/j.1365-3040.2007.01764.x

Verbruggen, N., Hermans, C., and Schat, H. (2009). Molecular mechanisms of metal hyperaccumulation in plants. New Phytol. 181, 759-776. doi: 10.1111/j.1469-8137.2008.02748.x

Visioli, G., and Marmiroli, N. (2013). The proteomics of heavy metal hyperaccumulation by plants. J. Proteomics 79, 133-145. doi: 10.1016/j.jprot. 2012.12.006
Visioli, G., Vincenzi, S., Marmiroli, M., and Marmiroli, N. (2012). Correlation between phenotype and proteome in the $\mathrm{Ni}$ hyperaccumulator Noccaea caerulescens subsp. caerulescens. Environ. Exp. Bot. 77, 156-164. doi: 10.1016/j.envexpbot.2011.11.016

Weber, M., Harada, E., Vess, C., Roepenack-Lahaye, E. V., and Clemens, S. (2004). Comparative microarray analysis of Arabidopsis thaliana and Arabidopsis halleri roots identifies nicotianamine synthase, a ZIP transporter and other genes as potential metal hyperaccumulation factors. Plant J. 37, 269-281. doi: 10.1046/j.1365-313X.2003.01960.x

Wittig, I., and Schägger, H. (2009). Native electrophoretic techniques to identify protein-protein interactions. Proteomics 9, 5214-5223. doi: 10.1002/pmic.200900151

Zeng, X.-W., Qiu, R.-L., Ying, R.-R., Tang, Y.-T., Tang, L., and Fang, X.-H. (2011). The differentiallyexpressed proteome in $\mathrm{Zn} / \mathrm{Cd}$ hyperaccumulator Arabis paniculata Franch. in response to $\mathrm{Zn}$ and Cd. Chemosphere 82, 321-328. doi: 10.1016/j.chemosphere.2010.10.030

Zhao, L., Sun, Y.-L., Cui, S.-X., Chen, M., Yang, H.-M., Liu, H.-M., et al.
(2011). Cd-induced changes in leaf proteome of the hyperaccumulator plant Phytolacca americana. Chemosphere 85, 56-66. doi: 10.1016/j.chemosphere.2011.06.029

Conflict of Interest Statement: The authors declare that the research was conducted in the absence of any commercial or financial relationships that could be construed as a potential conflict of interest.

Received: 14 May 2013; accepted: 09 July 2013; published online: 26 July 2013.

Citation: DalCorso G, Fasani $E$ and Furini A (2013) Recent advances in the analysis of metal hyperaccumulation and hypertolerance in plants using proteomics. Front. Plant Sci. 4:280. doi: 10.3389/fpls.2013.00280

This article was submitted to Frontiers in Plant Physiology, a specialty of Frontiers in Plant Science.

Copyright (C) 2013 DalCorso, Fasani and Furini. This is an open-access article distributed under the terms of the Creative Commons Attribution License, which permits use, distribution and reproduction in other forums, provided the original authors and source are credited and subject to any copyright notices concerning any third-party graphics etc. 